\title{
Analytical procedures for assessing effectiveness of spending on online advertising in medical organizations
}

\author{
Natalia Aleksandrovna Naumova \\ Candidate of Economic Sciences, Senior Lecturer, \\ Department of Economic Analysis and Audit, \\ Institute of Management, Economics and Finance \\ Kazan Federal University, \\ Kazan, 420008, Russia \\ naumovanataliy@mail.ru
}

\author{
Ilnara Ilnurovna Rahmanova \\ Candidate of Economic Sciences, Senior Lecturer, \\ Department of Economic Analysis and Audit, \\ Institute of Management, Economics and Finance \\ Kazan Federal University, \\ Kazan, 420008, Russia \\ ilra19@yandex.ru
}

\author{
Regina Vildanovna Nagumanova \\ Candidate of Economic Sciences, Associate Professor, \\ Department of Economic Analysis and Audit, \\ Institute of Management, Economics and Finance \\ Kazan Federal University, \\ Kazan, 420008, Russia
}

\begin{abstract}
The practical tool kit of an estimation efficiency of expenses for advertising in the Internet in medical organizations for proprietors, internal auditors, heads is reported. Theoretical material was collected from scientific journals, articles and books. By means of economic indicators analytical procedures according to estimation efficiency of expenses for online advertising are required.
\end{abstract}

Keywords - audit, online advertising, medical organization, economic indicators, auditor's report.

\section{INTRODUCTION}

Nowadays internal audit is an important management tool in medical organizations. The result of internal auditors working is the formation of distinct recommendations on improving the effectiveness of the organization. The results of commercial medical organizations working in the conditions of severe competition at market of medical services in Russia directly depend not only on the quality of provided services, but also on the effectiveness of the strategy for promoting the medical company itself. For studied medical organizations, the advertising budget reached up to $3 \%$ of total revenues. Currently, advertising is the main driving force for the development and growth of any company. It should be noted that there are more cases when potential patients use the Internet to find information about their diseases. According to the search system Yandex [8]: "Health is one of the most popular search themes in the Internet. It devoted more than $4 \%$ of search requests, which is almost 7.5 million a day. This is one of the biggest search topics - twice as large as cooking, and about the same as cars and everything related to them. Yandex is asked about health more than 5 thousand times every minute. The three biggest topics are related to searching information about medicines, about diseases and symptoms, about clinics and doctors.". Thus, a modern medical company simply must be represented on the Internet. Therefore, consideration of issues for evaluating the effectiveness of advertising expenses on the Internet is especially important.

Hypothesis: The owners and leaders of medical organizations are mostly medical workers, but not specialists in the field of advertising and promotion of the company, so they need a clear practical guide for assessing the effectiveness spending on advertising on the Internet.

\section{METHOD}

To achieve the goal, we had a review of the theoretical material, we studied advertising campaigns in the Internet of various commercial medical organizations in one of the regions of the Russian Federation - the Republic of Tatarstan.

\section{RESULTS}

Internal audit of advertising expenses in the Internet - a comprehensive, continuous inspection, which represents a certain sequence of actions to improve the efficiency of expenses [3]. The main objectives of advertising expenses in the Internet in internal audit are to establish the reliability and efficiency of the costs incurred. 
The algorithm for determining the reliability of advertising costs in the Internet was considered by the authors Kerimova C.V. [4], Spirina S.G [7], Egorian L.B. [1], Naumova N.A. [5, 6].

To realize the second goal: to evaluate the effectiveness of spending on advertising in the Internet, it is also necessary to understand its existing diversity. So, advertising in the Internet can be presented in the form of: banner advertising, search advertising, e-mail distribution, advertising in social networks, mobile services, etc. The current owner, the head of the medical organization, it is important to determine the extent of advertising format in the Internet was effective or not and to outline the further development strategy for the advertising company of the medical organization. When evaluating the effectiveness of advertising expenses in the Internet for medical activities, we do not recommend using standard approaches. For example, the standard indicators of involvement in the social networks of the organization are the growth of subscribers, "likes", etc., which is not typical for groups of medical organizations in social networks. This can be explained by the fact that social networks are an open source of information and potential patients try not to publicize the nature of their medical problems. Despite this, in order to evaluate the effectiveness of an advertising company in the Internet in medical organizations, there should be developed an indicator that allows to reconcile the money costs incurred and the amount of income obtained as a result of attracting new patients and loyalty of existing patients. We recommend using the LTV index, or the "lifetime value", as the main similar tool for estimating the efficiency of the expenses incurred in the Internet. It indicates the planned income from the patient, which can be obtained for the whole of its "lifetime value". The LTV index also allows to estimate the amount of funds that can be spent in the future to attract new clients (patients).

The following data were collected and studied in such medical organizations: the monthly number of new patients ("unique patients") and the amount of income received from the services rendered, the monthly amount of advertising expenses in the Internet to attract them. Table 1 is an example of the data received from the study of medical organization. In the process of studying the data we have encountered a number of problems that do not allow us to calculate the LTV index for studying medical organizations. Firstly, the data of Table 1 show the fact that unique patients, attracted in January, continue to visit studying medical clinic for the present and their number is decreasing. To calculate the LTV index, it is necessary to determine the period $(\mathrm{T})$ or "life cycle" of the patient, but in studying medical clinics, the patients continue to visit the organization and their "life cycle" has not yet ended.
TABLE I. THE DATA RECEIVED FROM THE STUDY OF MEDICAL ORGANIZATION.

\begin{tabular}{|l|l|l|}
\hline \multicolumn{1}{|c|}{ Date } & \multicolumn{1}{|c|}{ Number of patients } & Income, kRUB. \\
\hline January & 1300 & 4900 \\
\hline 02.17 & 180 & 1100 \\
\hline 03.17 & 95 & 890 \\
\hline 04.17 & 60 & 300 \\
\hline 05.17 & 55 & 120 \\
\hline 06.17 & 35 & 40 \\
\hline 07.17 & 40 & 90 \\
\hline$\ldots$ & $\ldots$ & $\ldots$ \\
\hline 04.18 & 25 & 35 \\
\hline
\end{tabular}

Secondly, data in Table 1 do not allow us to determine the most effective measures and the Internet platforms for advertising.

To solve the problems, we propose to group the data by months with a specified conditional period $\mathrm{T}=1, \mathrm{~T}=2, \mathrm{~T}=$ $3, \mathrm{~T}=4$.

TABLE II. THE DATA GROUPED BY MONTHS

\begin{tabular}{|l|l|l|l|}
\hline \multicolumn{1}{|c|}{$\begin{array}{c}\text { Name of } \\
\text { indicator }\end{array}$} & \multicolumn{1}{|c|}{$\begin{array}{c}\text { Number of } \\
\text { patients }\end{array}$} & Income, kRUB & $\begin{array}{c}\text { Avg. Income } \\
\text { per patient, } \\
\text { kRUB }\end{array}$ \\
\hline $\begin{array}{l}\text { Unique patients } \\
\text { in January }\end{array}$ & 1480 & 6000 & 4,1 \\
\hline $\begin{array}{l}\text { Unique patients } \\
\text { in February }\end{array}$ & 2350 & 9890 & 4,2 \\
\hline $\begin{array}{l}\text { Unique patients } \\
\text { in March }\end{array}$ & 1128 & 4350 & 3,9 \\
\hline $\begin{array}{l}\text { Unique patients } \\
\text { in April }\end{array}$ & 1950 & 8395 & 4,3 \\
\hline
\end{tabular}

Table 2 is a fragment of obtained data. We grouped the unique patients and the income received from the medical services rendered to them for a period (T) which is equal to two months and determined the average of income per unique patient for 2 months. Then, we recommend to compare data of the Table with the marketing activities conducted and assess the most effective ones. The highest return per patient was received in April 2017. There was carried out an enhanced advertising in the Yandex search system.

\section{CONCLUSIONS}

The proposed method of evaluating the effective advertising in the Internet is with some shortcomings. Among them are: the need of software products for calculating unique patients, the need to test various types of advertising in the Internet, which sometimes can lead to negative consequences. Nevertheless, this algorithm for determining the effectiveness of spending on Internet advertising allows one to link the money costs incurred and the amount of income received as a result of attracting new patients and existing patients.

For today, Russian and abroad medical organizations use the Internet for their advancement in the struggle for the patient in an acutely competitive market. These organizations are in a great need of practical tools for evaluating the effective costs of advertising in the Internet. 
The approach which is considered in the article will allow one to establish the effectiveness of advertising expenses as quickly as possible and select the most marginal areas for advertising of medical organization in the Internet.

\section{References}

[1] L.B. Egorian, "Click-fraud", as an actual problem to assess the effectiveness of Internet advertising: the methods of identification and solutions, Transport business of Russia, 2015, No. 1 (116), part 2, pp. 32-35.

[2] L.B. Egorian, New areas of application web analytics: social networks and the blog sphere, The Auditor, 2015, No. 6 (244), pp. 4348.

[3] N.D. Ilyenkova System analysis of competitiveness as a condition of economic security, Economics, Enterprise, Environment. International Journal,Moscow: MAEP, 2012, No. 49, pp. 35-39.

[4] Ch.V. Kerimova, Methods of collecting accounting and analytical information for the development and implementation of advertising projects, The financial bulletin: the finance, taxes, insurance, book keeping, M .: Book edition Finance, 2012, №1, pp. 53-64.

[5] N.A. Naumova, Internal audit of the effectiveness in commercial medical organizations, Practical medicine, 2013, No. 1-4 (73), pp. $117-120$.

[6] N.A. Naumova, R.V. Nagumanova, I.I. Rakhmanova, Internal audit of advertising expenses in the Internet in a commercial medical clinic, Management of economic systems: electronic journal, 2018, No. 4.

[7] S.G. Spirina, D.A. Golman, Formation of the effectiveness Internet advertising and its evaluation in the context of financial stability of the region's economy, Finance and credit, 2014, No. 37 (613), pp. 3241.

[8] Monthly reports Web Index, TNS Russia, Media and Custom Research. Retrieved from: http://mediascope.net/services/media/mediaaudience/internet/description

[9] Lipnická Denisa, Marketing audit and factors influencing its use in practice in companies, Journal of competitiveness, 2013, pp. 26-27.

[10] B. Clifton, Advanced Web Metrics with Google Analytics / Brian Clifton, John \& Wiley \& Sons, 2012. 
